\title{
Pathway analysis of cancer-associated microRNA targets
}

\author{
HAO YANG ${ }^{1 *}$, HAIYANG ZHANG ${ }^{1 *}$, LIN ZHU $^{2}$, JIN WANG $^{1}$, CHENYU ZHANG $^{1}$ and DONGHAI LI ${ }^{1}$ \\ ${ }^{1}$ Jiangsu Engineering Research Center for microRNA Biology and Biotechnology, State Key Laboratory of \\ Pharmaceutical Biotechnology, School of Life Sciences, Nanjing University, Nanjing $210093 ;{ }^{2}$ Institute of \\ Discovery Biology, Jiangsu Simcere Pharmaceutical R\&D Co. Ltd, Nanjing 210042, P.R. China
}

Received July 10, 2012; Accepted September 3, 2012

DOI: $10.3892 /$ ijo.2012.1658

\begin{abstract}
Carcinogenesis is a multi-step process, which includes oncogene activation, mutation silencing of tumor suppressor genes, impairment of chromosomes or epigenetic changes such as $\mathrm{CpG}$ island methylation through various cellular pathways, involving a series of somatic genetic alterations. Furthermore, miRNAs present a mechanism by which genes with diverse functions on multiple pathways can be simultaneously regulated at the post-transcriptional level. However, little is known about the cancer-related pathways through which cancer-associated miRNAs (CA-miRNAs) regulate these processes representing either positive or negative functions in carcinogenesis. This study investigated eleven miRNAs previously identified as cancer-related regulators. Using function and pathway analysis of their targeted genes, the relevance of miRNA regulation in the induction of cancer can be observed. The results showed that CA-miRNAs may function in the post-transcriptional level mainly through manipulating the expression of transcription factors and protein kinases, and target genes for the CA-miRNAs were most prominently predicted to function in the regulation of transcription. Our analysis also highlighted the potential of these CA-miRNAs to regulate the cell differentiation, proliferation, endocytosis and migration signaling logically required to cause a cancer cell mainly through five canonical pathways. Combined with previous cancer studies, the analysis of the relevance between functions of CA-miRNAs and cancer-related pathways exploring different internal carcinogenesis stimuli also revealed the potential of the top five pathways to regulate core carcinogenesis processes. These findings should form a useful knowledge base for potential future development of novel therapeutic treatments.
\end{abstract}

Correspondence to: Professor Donghai Li, Jiangsu Engineering Research Center for microRNA Biology and Biotechnology, State Key Laboratory of Pharmaceutical Biotechnology, School of Life Sciences, Nanjing University, 22 Hankou Road, Nanjing 210093, P.R. China

E-mail: donghaili@nju.edu.cn

*Contributed equally

Key words: cancer, microRNA, pathway, tumor suppressor, oncogene

\section{Introduction}

MiRNAs are short non-coding RNAs of 16 to 25 nucleotides in length. Longer precursor transcripts with hairpin structures are first synthesized by RNA polymerase II and mature miRNAs are generated after processing of the precursors by Drosha and Dicer ribonucleases (1). Depending on the degree of homology to their target sequence, miRNAs induce translational repression or cleavage of mRNAs. A single miRNA can target hundreds to a thousand or more mRNAs (2), rendering it challenging to attribute distinct functions to specific miRNAs. Perhaps as a result of this complexity, in spite of the evolutionary conservation of miRNAs, their function in physiology and disease remains rather enigmatic. Our research group has demonstrated that exogenous plant miRNAs in food can regulate the expression of target genes in mammals which suggested that miRNA may have a powerful ability to regulate gene expressions (3). Aberrations or corruptions of miRNA functions may lead to deregulated cell proliferation, tumorigenesis, and ultimately, cancer. Moreover, signaling pathways of the core components of cancer cells also take part in the post-transcriptional regulation of miRNAs (4).

Cancer is characterized by abnormal cell proliferation that undergoes rapid, uncoordinated cell growth. Malignant cancer, in contrast to benign cancer, is further hallmarked by aggressive neoplasms that have the ability to invade and annihilate adjacent tissues and metastasize to more distant and sometimes specific tissues. Genes involved in cancer, be it inceptionally or during the later invasive or metastasis stages, are generally classified into oncogenes (OG) or tumor suppressor (TS) genes. During the last decade, a unique set of cancer regulator miRNAs have emerged and these are divided into oncomiRs and antioncomiRs. OncomiRs and anti-oncomiRs negatively regulate tumors uppressor genes and oncogenes, respectively.

Differential miRNA expression profiles of cancerous and normal tissues have revealed signatures that facilitate identifying and monitoring cancers (5). Researchers are now trying to use these miRNA signatures therapeutically to support diagnosis, prognosis or treatment of cancer. Instead of detailing the whole body of identified oncomiRs and anti-oncomiRs (6,7), the focus is on illustrating mechanistically how the miRNA pathway is involved, or affected by, cancer at the hand of representative examples (8).

A biological pathway, which is a series of actions among molecules in a cell that leads to a certain product or a change in a 
cell, can trigger the assembly of new molecules or turn genes on and off, or spur a cell to move. Identifying what genes, proteins and other molecules are involved in a biological pathway can provide clues on what goes wrong when a disease strikes. The most common pathways are involved in metabolism, the regulation of genes and the transmission of signals. Deregulation of miRNAs are involved in the process of cell proliferation activation, apoptosis signaling pathway inactivation, as well as other genetic changes, which together lead to cancer pathogenesis. Hitherto, accumulating evidence has demonstrated that miRNAs are involved in mediating several cancer-related pathways linked to programmed cell death (PCD), indicating that miRNAs may function as the key regulators in apoptosis and autophagy of cancer (9). Recent projects that deciphered the different expressions of miRNAs in a certain cancer by RT-qPCR after Solexa or Microarry screening only have found an array of different mutations of miRNAs in different samples, then the pathway involved by the most different expressed miRNAs can be figured out. The problem is that these kinds of methods only could find one miRNA-related pathway in a certain cancer. miRNAs commonly involved in several cancers would function as key regulators of many more cancer-related pathways, which may be a link between the cancer-related pathway research and function research of miRNAs.

The development of pathway strategies for the analysis of cancer raises the question of whether one can use these approaches to characterize and treat human cancer. Identifying the molecular causes of cancer represented a major breakthrough in the history of medicine, moving the discipline from pattern recognition and therapeutic strategies based on syndromic pathophysiology to molecular mechanism and evidence-based therapies derived from clinical trials designed on the basis of molecular mechanism (10).

In this study, we summarized 11 common CA-miRNAs from previous observations. Many of these CA-miRNAs were located near genomic breakpoints (11). For example, miR-15/16-1 cluster is located within a $30-\mathrm{kb}$ region of chromosome $13 q 14$ and that both genes are deleted or downregulated in the majority (approximately 68\%) of B cell chronic lymphocytic leukemia (CLL) cases (12). On the other hand, one cluster of microRNAs, the miR-17-92 polycistron, is located in a region of DNA that is amplified in human B cell lymphomas (13). Upregulated expression of the mature miRNAs from miR-17-92 cluster, has been confirmed in a wide range of tumor-derived cell lines (14). Protein class, molecular functions, biological processes and canonical pathways involved by the targets of each CA-miRNA as well as 5 main canonical pathways participated by certain CA-miRNAs, were identified and analyzed, which may offer significant treatment clues for the clinical therapy of cancer.

\section{Materials and methods}

Targets analysis of each CA-miRNAs. MiRNA targeting is mostly achieved through specific base-pairing interactions between the 5 ' end ('seed' region) of the miRNA and sites within coding and untranslated regions (UTRs) of mRNAs; target sites in the 3'UTR lead to more effective mRNA destabilization (15). The expression of a single target gene of a certain miRNA may not provide enough information on the role of that miRNA in the analyzed pathophysiological process (16). Therefore, we used a widely-used and web-based software Targetscan (http://www. targetscan.org) to generate lists of possible gene targets of each CA-miRNA. Then we input the targeted genes into another web server Panther (http://www.pantherdb.org/) which is designed for gene function cluster and we gained the protein class from the panther analysis. After that, we clustered the same function class of protein with top ten classes.

The web-based functional annotation tool Database for Annotation, Visualization and Integrated Discovery (DAVID) v6.7 (http://david.abcc.ncifcrf.gov/tools.jsp) has key components for disease analysis, gene ontology analysis and pathway analysis (17).

Pathway mapping of cancer-associated miRNA targets. The signaling pathways and processes that these gene targets are involved in were explored using the systems biology tool KEGG Mapper (http://www.genome.jp/kegg/tool/map_pathway2. html). This KEGG database, containing 291 known pathways on molecular interactions and reaction networks, pathways and processes (18), allows the user to visualize known biological systems within their data.

\section{Results and Discussion}

Cancer-associated miRNAs (CA-miRNAs). Functional studies performed in cancer cell lines or mouse models with various malignancies through overexpression or knockdown of miRNAs have supported a role for some of these miRNAs in carcinogenesis (15). Based on previous experimental data, 11 CA-miRNAs are summarized as the most common cancerassociated miRNAs (Table I). The miRNA dysregulation could drive tumorigenesis, although the roles miRNAs can adopt as tumor suppressors or oncogenes.

Let-7 is an anti-oncomiR and conserved in many cancers. It functions as a post-transcriptional gatekeeper for cell proliferation process. For example, let-7 family negatively regulates RAS, a lung cancer oncogene involved in cancerous cells by disturbing cell cycle progression $(19,20)$. Let-7 family (let-7a to i) display a striking upregulation in differentiating SK-3rd cells and a high level of expression in the parental SK-BR-3 cells that have not been enriched for breast T-ICs13 (21).

MiR-9 has been strongly suggested to act as a putative tumor suppressor gene in recurrent ovarian cancer (22). In addition, it can be affected by epigenetic inactivation due to aberrant hypermethylation which is an early and frequent event in breast cancer development (23). The rescued expression of miR-9 could also promote medulloblastoma cell growth arrest and apoptosis while targeting the proliferative truncated TrkC isoform (24). On the other hand, some research groups have reported that the level of miR-9 is upregulated in breast cancer cells by directly targeting CDH1, the E-cadherin-encoding mRNA, which could lead to increased cell motility and invasiveness. MiR-9-mediated E-cadherin downregulation results in the activation of $\beta$-catenin signaling pathway, which could contribute to upregulated expression of the gene encoding vascular endothelial growth factor (VEGF); this would in turn lead to an increase of tumor angiogenesis. Certain miRNA may mediate c-Myc induced mammary carcinogenesis (25). At the same time, expression of miR-9 could also be activated by MYC and MYCN, both of 
Table I. Prediction of each CA-miRNA target.

\begin{tabular}{lc}
\hline CA-miRNAs & No. of predicted target genes \\
\hline let-7 family & 1,072 \\
miR-9 & 1,237 \\
miR-15a/16-1 cluster & 1,273 \\
miR-17-92 family & 2,656 \\
miR-21 & 164 \\
miR-26a & 186 \\
miR-34a/b/c & 852 \\
miR-155 & 440 \\
miR-200/141 family & 744 \\
miR-205 & 416 \\
miR-206 & 102 \\
\hline
\end{tabular}

which directly bind to the mir-9-3 locus (26), which seem to be an obvious evidence of feedback loop regulation.

MiR-15a and miR-16-1 act as putative tumor suppressors by targeting the oncogene BCL2. These miRNAs form a cluster at the chromosomal region of $13 \mathrm{q} 14$, which is frequently deleted in cancer. The miR-15a and miR-16-1 cluster targets CCND1 (encoding cyclin D1) and WNT3A, which promotes several tumorigenic features such as survival, proliferation and invasion. Deletion of miR-15a and miR-16-1 genes results in loss of apoptosis. For advanced prostate tumors, the level of miR-15a and miR-16 is significantly decreased, whereas the expression of BCL2, CCND1 and WNT3A is inversely upregulated (27). In chronic lymphocytic leukemia (CLL), miR-15a and miR-16-1 are mostly lost or downregulated in the majority of cases (28).

Overexpression of miRNAs encoded by the miR-17-92 cluster and its paralogs in multiple malignancies are known to act as oncogenes. Expression of these miRNAs promotes cell proliferation, suppresses apoptosis of cancer cells and induces tumor angiogenesis (29). Analysis of human medulloblastomas (MBs) demonstrated that 3 miR-17-92 cluster miRNAs (miR-92, miR-19a and miR-20) were overexpressed in human MBs with a constitutively activated Sonic Hedgehog ( $\mathrm{SHH}$ ) signaling pathway, but not found in other forms of the disease (30).

MiR-21 expression is not only activated in multiple types of cancers, such as breast, liver, brain, prostate and myometrial cancers but also in different kinds of diseases, such as cardiovascular disease. MiR-21 regulates a plethora of target proteins which are involved in cellular survival, apoptosis and cell invasiveness. MiR-21 regulation is complex due to a promoter that is target for various transcription factors and hormones. The consistent miR-21 overexpression under pathophysiological conditions points to miR-21 as a valuable tool for new therapeutic strategies. The overexpression of certain oncogenic miRNAs (miR-21 and miR-155) and the loss of several tumor suppressor miRNAs (miR-206, miR-17-5p, miR-200, let-7 and miR-34) have been observed in many breast cancers. The gene networks orchestrated by these miRNAs are still largely unknown, although key targets have been identified that may contribute to the disease phenotype (31). MiR-155 was more highly expressed in activated $B$ cell-like (ABC)-type than germinal center B cell-like (GCB)-type cell lines, which are two subtypes of diffuse large B cell lymphoma (DLBCL) (32).
MiR-26a is frequently amplified at the DNA level in human glioma, most often in association with monoallelic PTEN loss (30). Ectopic expression of miR-26a influenced cell cycle progression by targeting the bona fide oncogene EZH2, a Polycomb protein and global regulator of gene expression (33). Its expression in liver cancer cells in vitro can induce cell cycle arrest, which may associate with direct targeting of cyclins D2 and E2 (34). A significant decrease in miR-26a was detected in growing anaplastic carcinomas (ATC) in comparison to normal thyroid tissue (35). MiR-26a, CDK4 and CENTG1 together comprise a functionally integrated oncomir/oncogene DNA cluster that promotes aggressiveness in human cancers by cooperatively targeting the RB1, PI3K/AKT and JNK pathways (36).

The miRNA-34 family comprises three members: miRNA-34a, miR-34b and miR-34c. MiR-34a is generated from a larger transcriptional unit on chromosome 1p36; and both of miR-34b and miR-34c are generated through the processing of a bicistronic transcript from chromosome 11q23 (termed miR-34bc). The miR-34 family members have also been identified as promising prognostic markers in non-small cell lung cancer (NSCLC); the family is downmodulated in tumors compared with normal tissue. Restoration of miR-34 expression in the pancreatic cancer cells by either transfection of miR-34 mimics or infection with lentivirus significantly inhibited clonogenic cell growth and invasion, induced apoptosis and G1 and G2/M arrest in the cell cycle, and sensitized the cells to chemotherapy and radiation (37). The likely growth inhibition mechanism of miR-34a, as a tumor suppressor gene in human neuroblastoma, is through cell cycle arrest followed by apoptosis. BCL2 and MYCN were identified as miR-34a targets and likely mediators of the tumor suppressor phenotypic effect (38). In HepG2 cells, ectopic expression of miR-34a potently inhibited tumor cell migration and invasion in a c-Met-dependent manner. It directly targeted c-Met and caused reduction of both mRNA and protein levels of c-Met; thus, decreased c-Met-induced phosphorylation of extracellular signal-regulated kinases 1 and 2 (ERK1/2) (39).

From a large-scale miRnome analysis on lung, breast, stomach, prostate, colon, and pancreatic tumors, some miRNAs have been found with well characterized cancer association, which include miR-155, miR-17-5p, miR-21, miR-92 and miR-106a (40). What is more, high miR-155 and low let-7a-2 expression correlated with poor survival has been found in lung cancer by univariate analysis as well as multivariate analysis for miR-155 (41).

Downregulation of miR-141 and miR-200c in renal clear cell carcinomas (CCCs) might be involved in suppression of CDH1/E-cadherin transcription via upregulating ZFHX1B (42). The expression of miR-141 was also found to be substantially reduced in several human gastric cancer cell lines such as MGC-803, HGC-27, SGC-7901 and BGC-823 cells. MiR-141 may be involved in the development of gastric cancer through its inhibitory effect on cell proliferation (43). Members of the miR-200 family appear to control the epithelial-to-mesenchymal transition (EMT) process, as well as the sensitivity to EGFR therapy in bladder cancer cells. Structural analysis of EGFR TK domain provides insights into EGFR targeted therapies (44). The expression of miR-200 is sufficient to restore EGFR dependency at least in some of the mesenchymal bladder cancer cells. The targets of miR-200 include ERRFI-1, which is a novel 
A

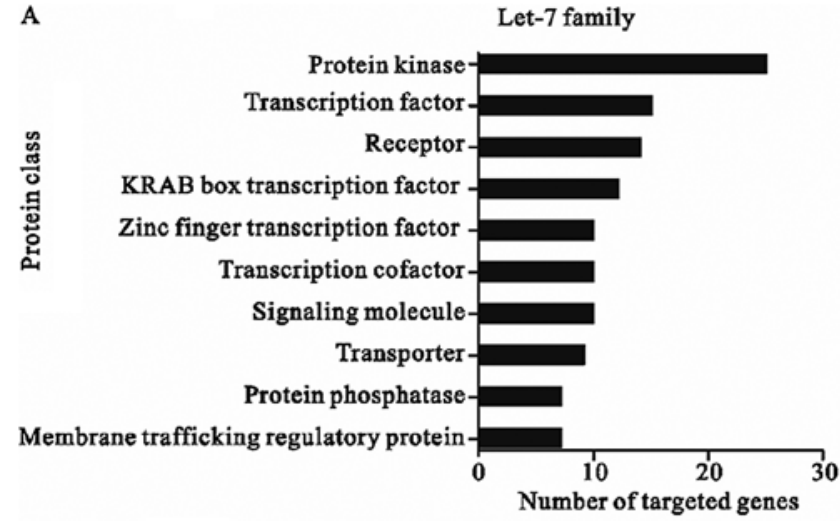

C

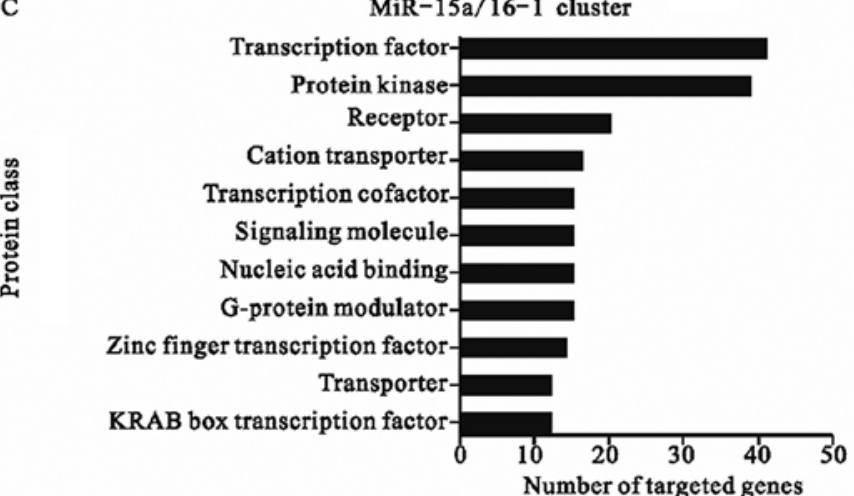

E

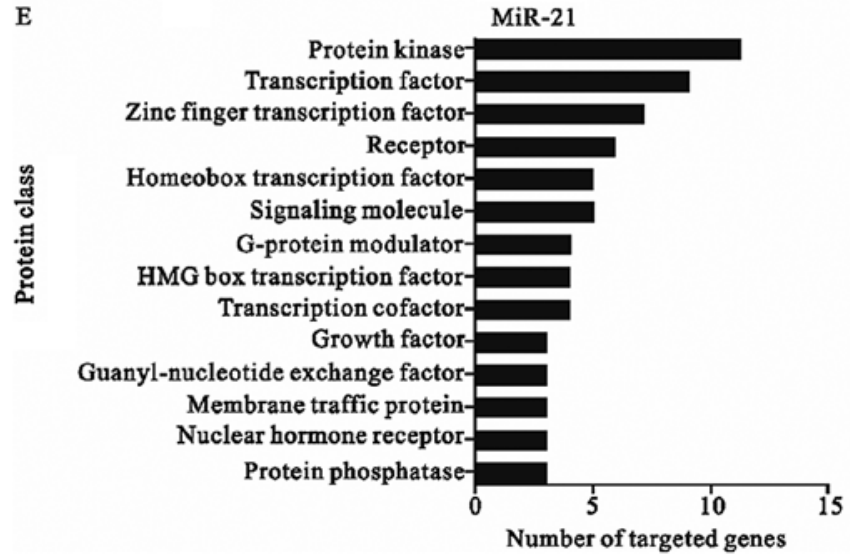

B

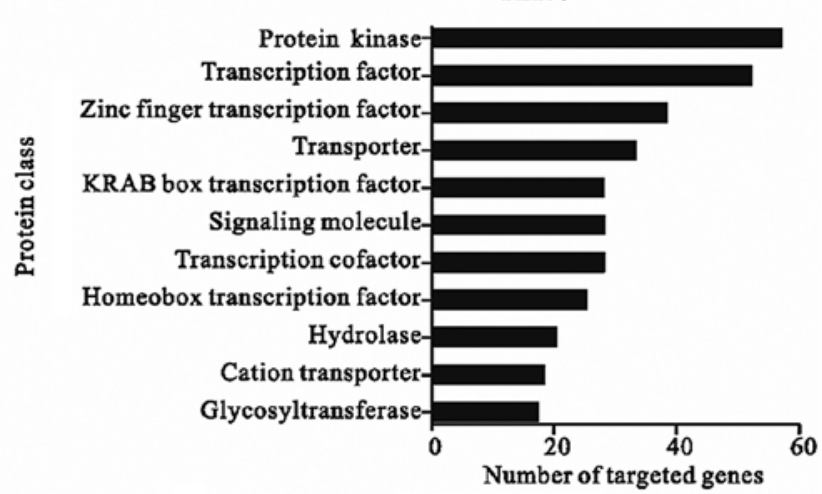

D

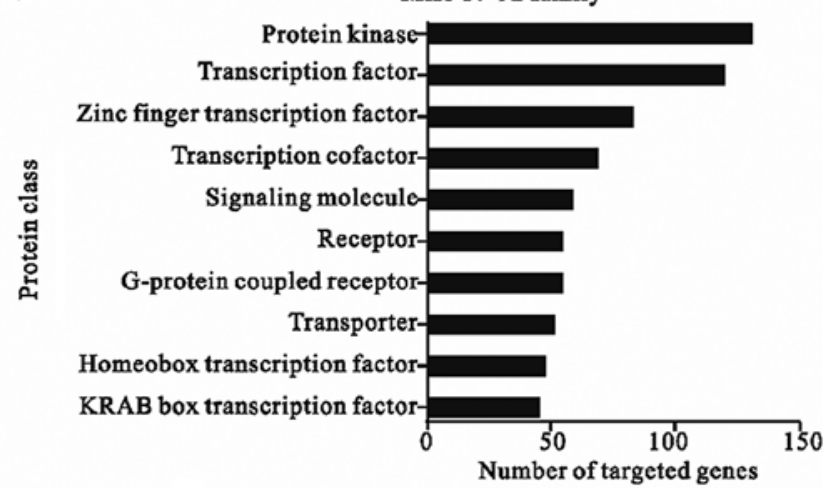

F

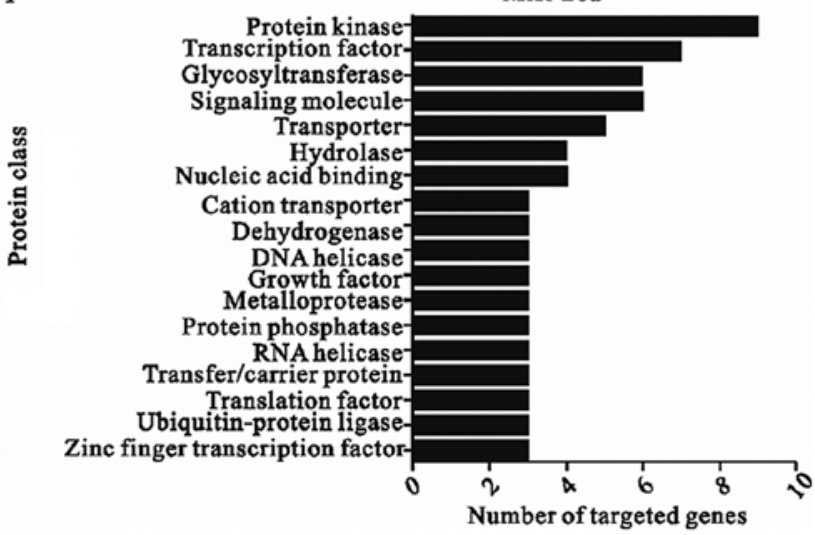

Figure 1. The major class of potential targets of CA-miRNAs.

regulator of EGFR-independent growth (45). On the contrary, in ovarian cancer miR-200 family members are expressed at low or negligible levels in normal ovarian surface cells and substantially increase in expression, whereas expression of ZEB1 and ZEB2 shows the opposite pattern (46).

MiR-205 exerts a tumor-suppressive effect in human prostate by counteracting EMT process and reducing cell migration/invasion, at least in part through the downregulation of protein kinase Ce (47). MiR-200 and miR-205 loci are repressive chromatin marks, in muscle invasive bladder tumors and undifferentiated bladder cell lines, which have been found specifically silenced and gain promoter hypermethylation (48). As a new oncosuppressor gene in breast cancer, miR-205 is able to interfere with the proliferative pathway mediated by kinase-inactive member HER receptor family (49). However, compared with normal tissues, the levels of miR-205, together with miR-21 and miR-203 were found to be significantly up-modulated in OVCAR3 cells which were demethylated with 5-aza-2'-deoxycytidine (50). This suggested that miR-205 also has a role as an oncomiRNA.

As the product of MET proto-oncogene, Met tyrosine-kinase receptor has been found overexpressed in human rhabdomyosarcoma (RMS) cell lines and involved in RMS pathogenesis. Upon the presence of miR-206, Met tyrosine-kinase receptor was down-regulated in murine satellite cells in the onset of normal myogenesis (51). Since there was no evidence of miR-206 activation in serum derivate RMS cell lines, miR-206 was suggested as tumor suppressor and has been identified to be involved in breast cancer metastasis (52).

Thus, let-7 family (let-7a to i), miR-15a/16-1 cluster, $\mathrm{miR}-34 \mathrm{a} / \mathrm{b} / \mathrm{c}$ and miR-206 are classified as anti-oncomiRs or TS (tumor suppressor), while miR-17-92 family (miR-17, miR-18a/b, miR-20a/b, miR-106a/b, miR-93, miR-19a/b, miR-25, miR-92a 
G

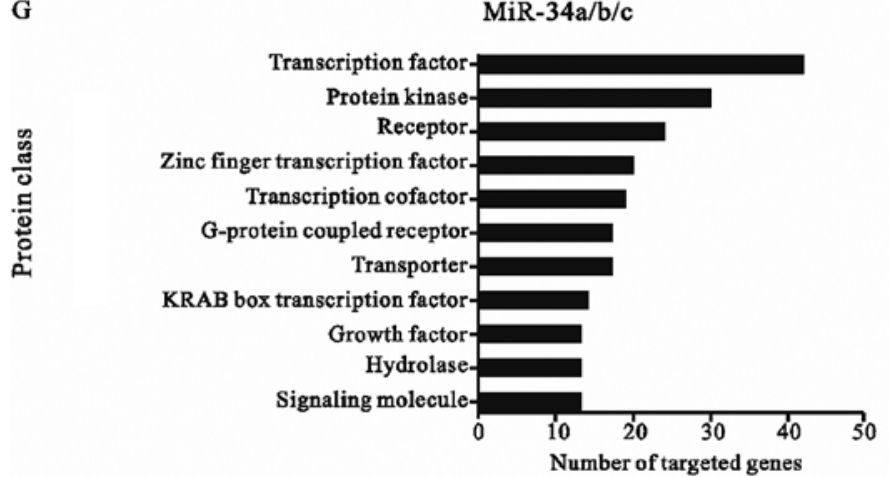

I

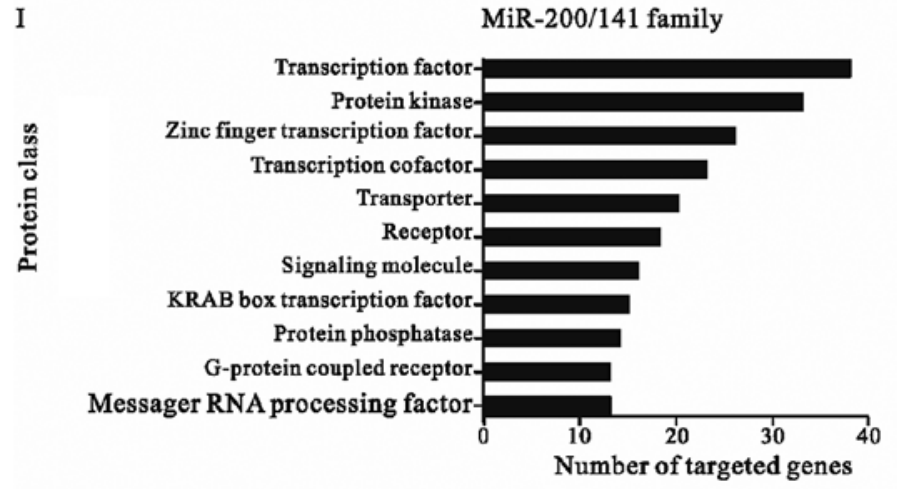

$\mathbf{K}$

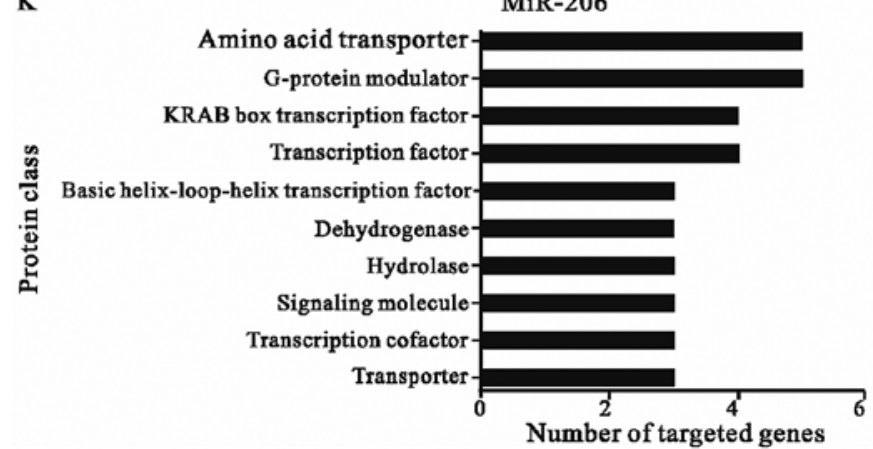

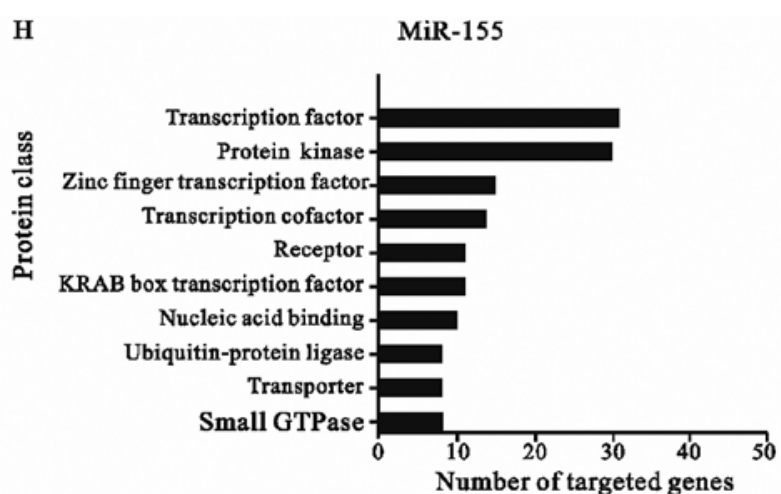

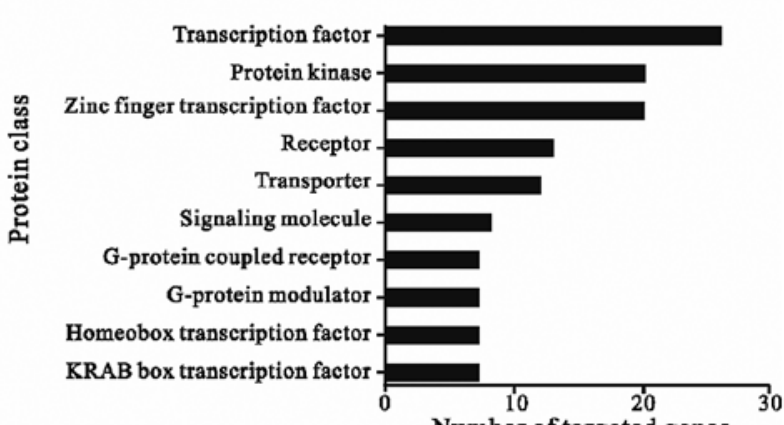

Figure 1. Continued.

and miR-363), miR-21 and miR-155 play the roles as oncomiRs or OG (oncogenes). What is more, miR-9, miR-26a, miR-200/141 family and miR-205 possess two kinds of effects which are either anti-oncomiRs or oncomiRs.

Predictions and protein classifications of CA-miRNA targets. The miRNAs have the capacity to 'tune' the expression of a target gene to a precise level (53). Therefore, investigation of target gene is one of the keys for understanding miRNAs. Each CA-miRNA or miRNA cluster has the ability to target between 102 and 2,656 mRNAs of predicted genes (Table I) and in addition some 3'UTRs of the mRNAs potentially have multiple complementary sites for a given miRNA. To add to the complexity, in fact this set of miRNAs may be a subset of the total number of miRNAs that play a role in cancer. Moreover, this result was consistent with the hypothesis that oncomiRs and anti-oncomiRs mainly interact with tumor suppressor genes and oncogenes, respectively (54).
A total of 5,001 unique targeted genes have been found that are 11 identified CA-miRNAs related. Of all the targeted genes, 1,850 items are from targets of anti-oncomiRs, so these genes are more likely upregulated in cancer cells. Accordingly, 2,971 downregulated targeted genes are discovered from that of oncomiRs and 2,204 ones from that of miRNAs which could act as either oncomiRs or anti-oncomiRs. Moreover, 12 common genes (BNC2, BRWD3, DCUN1D3, GATAD2B, KCNA1, KPNA4, PIK3R1, PURB, RBMS3, SATB1, SOCS6 and TGFBR2) were found in the targets of oncomiRs and with one gene the C5orf41, which was identified as a target of miRNAs either as oncomiRs or anti-oncomiRs. These common target genes can be potential cancer treatment targets.

The major classes of potential targets of each CA-miRNAs are shown in Fig. 1. These potential miRNA targets belong to a great many of gene families which play various roles during physiological and pathological processes. Although the different 
Table II. Molecular function and biological process analysis of each CA-miRNA.

\begin{tabular}{|c|c|c|c|}
\hline CA-miRNAs & $\begin{array}{c}\text { Molecular function } \\
\text { and biological process }\end{array}$ & $\begin{array}{c}\% \text { Regulated by } \\
\text { CA-miRNAs }\end{array}$ & P-value \\
\hline \multirow[t]{5}{*}{ let-7 family } & Regulation of transcription & $20.6 \%$ & $2.80 \mathrm{E}-04$ \\
\hline & Transcription & $14.4 \%$ & $5.20 \mathrm{E}-02$ \\
\hline & Regulation of transcription, DNA-dependent & $13.7 \%$ & $7.90 \mathrm{E}-03$ \\
\hline & Regulation of RNA metabolic process & $13.7 \%$ & $1.20 \mathrm{E}-02$ \\
\hline & Phosphorus metabolic process & $10.2 \%$ & $9.40 \mathrm{E}-05$ \\
\hline \multirow[t]{5}{*}{ miR-9 } & Regulation of transcription & $19.30 \%$ & $1.50 \mathrm{E}-06$ \\
\hline & Transcription & $15.20 \%$ & $1.40 \mathrm{E}-04$ \\
\hline & Regulation of RNA metabolic process & $14.00 \%$ & $6.70 \mathrm{E}-06$ \\
\hline & Regulation of transcription, DNA-dependent & $13.40 \%$ & $3.40 \mathrm{E}-05$ \\
\hline & Intracellular signaling cascade & $8.90 \%$ & $7.60 \mathrm{E}-03$ \\
\hline \multirow[t]{5}{*}{ miR-15a/16-1 cluster } & Regulation of transcription & $18.90 \%$ & 4.70E-04 \\
\hline & Transcription & $14.80 \%$ & $7.00 \mathrm{E}-03$ \\
\hline & Regulation of RNA metabolic process & $12.00 \%$ & $5.30 \mathrm{E}-02$ \\
\hline & Intracellular signaling cascade & $9.00 \%$ & $2.50 \mathrm{E}-02$ \\
\hline & Phosphate metabolic process & $8.90 \%$ & $1.10 \mathrm{E}-04$ \\
\hline \multirow[t]{5}{*}{ miR-17-92 family } & Regulation of transcription & $21.00 \%$ & $1.20 \mathrm{E}-24$ \\
\hline & Transcription & $16.70 \%$ & $1.20 \mathrm{E}-17$ \\
\hline & Regulation of RNA metabolic process & $14.30 \%$ & $3.00 \mathrm{E}-14$ \\
\hline & Regulation of transcription, DNA-dependent & $13.90 \%$ & $2.50 \mathrm{E}-13$ \\
\hline & Intracellular signaling cascade & $10.10 \%$ & $3.80 \mathrm{E}-11$ \\
\hline \multirow[t]{5}{*}{$\operatorname{miR}-21$} & Regulation of transcription & $23.30 \%$ & $2.90 \mathrm{E}-03$ \\
\hline & Regulation of RNA metabolic process & $18.40 \%$ & $1.70 \mathrm{E}-03$ \\
\hline & Transcription & $17.80 \%$ & $2.40 \mathrm{E}-02$ \\
\hline & Regulation of transcription, DNA-dependent & $17.20 \%$ & $5.00 \mathrm{E}-03$ \\
\hline & Positive regulation of macromolecule metabolic process & $14.70 \%$ & $2.80 \mathrm{E}-06$ \\
\hline \multirow[t]{5}{*}{ miR-26a } & Transcription & $15.10 \%$ & $9.60 \mathrm{E}-02$ \\
\hline & Phosphorus metabolic process & $11.40 \%$ & $1.60 \mathrm{E}-03$ \\
\hline & Phosphate metabolic process & $11.40 \%$ & $1.60 \mathrm{E}-03$ \\
\hline & Phosphorylation & $9.20 \%$ & $6.10 \mathrm{E}-03$ \\
\hline & Protein amino acid phosphorylation & $8.60 \%$ & $2.70 \mathrm{E}-03$ \\
\hline \multirow[t]{5}{*}{$\mathrm{miR}-34 \mathrm{a} / \mathrm{b} / \mathrm{c}$} & Regulation of transcription & $19.20 \%$ & 4.80E-05 \\
\hline & Transcription & $15.30 \%$ & $6.30 \mathrm{E}-04$ \\
\hline & Regulation of RNA metabolic process & $13.50 \%$ & 7.30E-04 \\
\hline & Regulation of transcription, DNA-dependent & $13.10 \%$ & $1.10 \mathrm{E}-03$ \\
\hline & Positive regulation of macromolecule metabolic process & $7.40 \%$ & $5.10 \mathrm{E}-04$ \\
\hline \multirow[t]{5}{*}{$\operatorname{miR}-155$} & Regulation of transcription & $29.30 \%$ & $1.30 \mathrm{E}-14$ \\
\hline & Transcription & $23.80 \%$ & $1.20 \mathrm{E}-11$ \\
\hline & Regulation of transcription, DNA-dependent & $19.00 \%$ & 4.50E-08 \\
\hline & Regulation of RNA metabolic process & $19.00 \%$ & $1.20 \mathrm{E}-07$ \\
\hline & Intracellular signaling cascade & $12.40 \%$ & $2.00 \mathrm{E}-04$ \\
\hline \multirow[t]{5}{*}{ miR-200/141 family } & Regulation of transcription & $21.50 \%$ & $1.90 \mathrm{E}-07$ \\
\hline & Transcription & $18.10 \%$ & $3.50 \mathrm{E}-07$ \\
\hline & Regulation of RNA metabolic process & $16.40 \%$ & $1.00 \mathrm{E}-07$ \\
\hline & Regulation of transcription, DNA-dependent & $15.40 \%$ & $1.90 \mathrm{E}-06$ \\
\hline & Intracellular signaling cascade & $9.80 \%$ & $4.50 \mathrm{E}-03$ \\
\hline \multirow{5}{*}{ miR-205 } & Regulation of transcription & $22.50 \%$ & $6.90 \mathrm{E}-06$ \\
\hline & Transcription & $18.60 \%$ & $3.10 \mathrm{E}-05$ \\
\hline & Regulation of transcription, DNA-dependent & $16.20 \%$ & $5.50 \mathrm{E}-05$ \\
\hline & Regulation of RNA metabolic process & $16.20 \%$ & $1.10 \mathrm{E}-04$ \\
\hline & Positive regulation of macromolecule metabolic process & $11.80 \%$ & $1.60 \mathrm{E}-08$ \\
\hline \multirow{5}{*}{$\operatorname{miR}-206$} & Transcription & $21.60 \%$ & $9.00 \mathrm{E}-03$ \\
\hline & Regulation of transcription & $21.60 \%$ & $7.20 \mathrm{E}-02$ \\
\hline & Intracellular signaling cascade & $12.40 \%$ & $8.50 \mathrm{E}-02$ \\
\hline & Protein localization & $11.30 \%$ & $2.30 \mathrm{E}-02$ \\
\hline & Protein transport & $9.30 \%$ & $6.00 \mathrm{E}-02$ \\
\hline
\end{tabular}


Table III. Canonical pathway analysis of each CA-miRNA.

\begin{tabular}{|c|c|c|c|}
\hline CA-miRNAs & Canonical pathways & $\begin{array}{c}\% \text { Regulated by } \\
\text { CA-miRNAs }\end{array}$ & P-value \\
\hline \multirow[t]{4}{*}{ let-7 family } & Pathways in cancer & $4.20 \%$ & $9.00 \mathrm{E}-04$ \\
\hline & MAPK signaling pathway & $3.70 \%$ & $9.60 \mathrm{E}-04$ \\
\hline & p53 signaling pathway & $2.00 \%$ & 4.30E-04 \\
\hline & mTOR signaling pathway & $1.20 \%$ & $2.10 \mathrm{E}-02$ \\
\hline \multirow[t]{5}{*}{$\operatorname{miR}-9$} & Pathways in cancer & $3.40 \%$ & $2.60 \mathrm{E}-05$ \\
\hline & MAPK signaling pathway & $2.60 \%$ & $5.40 \mathrm{E}-04$ \\
\hline & Focal adhesion & $2.50 \%$ & $1.60 \mathrm{E}-05$ \\
\hline & Endocytosis & $2.10 \%$ & $1.70 \mathrm{E}-04$ \\
\hline & Regulation of actin cytoskeleton & $2.10 \%$ & $1.80 \mathrm{E}-03$ \\
\hline \multirow[t]{5}{*}{ miR-15a/16-1 cluster } & Pathways in cancer & $4.00 \%$ & 2.30E-08 \\
\hline & MAPK signaling pathway & $2.90 \%$ & $2.00 \mathrm{E}-06$ \\
\hline & Neurotrophin signaling pathway & $2.30 \%$ & 7.00E-05 \\
\hline & Insulin signaling pathway & $1.70 \%$ & $1.40 \mathrm{E}-02$ \\
\hline & p53 signaling pathway & $1.10 \%$ & $1.50 \mathrm{E}-02$ \\
\hline \multirow[t]{5}{*}{ miR-17-92 family } & Pathways in cancer & $2.80 \%$ & $1.60 \mathrm{E}-05$ \\
\hline & MAPK signaling pathway & $2.70 \%$ & $1.90 \mathrm{E}-08$ \\
\hline & Endocytosis & $2.20 \%$ & $8.00 \mathrm{E}-10$ \\
\hline & Regulation of actin cytoskeleton & $1.80 \%$ & $3.70 \mathrm{E}-04$ \\
\hline & Focal adhesion & $1.80 \%$ & $1.40 \mathrm{E}-04$ \\
\hline \multirow[t]{5}{*}{$\operatorname{miR}-21$} & MAPK signaling pathway & $6.70 \%$ & $1.20 \mathrm{E}-04$ \\
\hline & Pathways in cancer & $5.50 \%$ & $9.50 \mathrm{E}-03$ \\
\hline & Cytokine-cytokine receptor interaction & $4.90 \%$ & $9.50 \mathrm{E}-03$ \\
\hline & Jak-STAT signaling pathway & $4.30 \%$ & $2.80 \mathrm{E}-03$ \\
\hline & Pancreatic cancer & $3.70 \%$ & 4.80E-04 \\
\hline miR-26a & Wnt signaling pathway & $2.70 \%$ & $1.90 \mathrm{E}-02$ \\
\hline \multirow[t]{5}{*}{$\mathrm{miR}-34 \mathrm{a} / \mathrm{b} / \mathrm{c}$} & Pathways in cancer & $3.40 \%$ & $1.10 \mathrm{E}-03$ \\
\hline & MAPK signaling pathway & $2.40 \%$ & $2.60 \mathrm{E}-02$ \\
\hline & Focal adhesion & $2.30 \%$ & $3.10 \mathrm{E}-03$ \\
\hline & Endocytosis & $1.90 \%$ & $1.60 \mathrm{E}-02$ \\
\hline & Regulation of actin cytoskeleton & $1.90 \%$ & $5.20 \mathrm{E}-02$ \\
\hline \multirow[t]{5}{*}{$\operatorname{miR}-155$} & Pathways in cancer & $5.50 \%$ & $5.20 \mathrm{E}-06$ \\
\hline & MAPK signaling pathway & $4.30 \%$ & $1.10 \mathrm{E}-04$ \\
\hline & $\mathrm{T}$ cell receptor signaling pathway & $3.70 \%$ & 5.50E-08 \\
\hline & Neurotrophin signaling pathway & $3.00 \%$ & $5.60 \mathrm{E}-05$ \\
\hline & B cell receptor signaling pathway & $2.50 \%$ & $1.50 \mathrm{E}-05$ \\
\hline \multirow[t]{5}{*}{ miR-200/141 family } & Pathways in cancer & $3.60 \%$ & $2.70 \mathrm{E}-04$ \\
\hline & MAPK signaling pathway & $2.80 \%$ & $3.30 \mathrm{E}-03$ \\
\hline & Wnt signaling pathway & $1.90 \%$ & $3.00 \mathrm{E}-03$ \\
\hline & Axon guidance & $1.50 \%$ & $1.80 \mathrm{E}-02$ \\
\hline & Chronic myeloid leukemia & $1.40 \%$ & $1.40 \mathrm{E}-03$ \\
\hline \multirow[t]{5}{*}{ miR-205 } & Tight junction & $2.70 \%$ & 8.80E-04 \\
\hline & Endocytosis & $2.50 \%$ & $2.40 \mathrm{E}-02$ \\
\hline & Wnt signaling pathway & $2.20 \%$ & $2.10 \mathrm{E}-02$ \\
\hline & Ubiquitin mediated proteolysis & $2.00 \%$ & $3.60 \mathrm{E}-02$ \\
\hline & Adherens junction & $1.50 \%$ & $3.00 \mathrm{E}-02$ \\
\hline miR-206 & Regulation of actin cytoskeleton & $4.10 \%$ & $5.70 \mathrm{E}-02$ \\
\hline
\end{tabular}

seed region sequences of these miRNAs leads to the diversity of different targets, the protein class of all the targeted genes seemed similar, suggesting that CA-miRNAs might function in the post-transcriptional level mainly through manipulating the expression of transcription factors and protein kinases. As a recently recognized part of that regulation, miRNA-mediated events seem to ensure the preciseness and fidelity of dynamic and spatially restricted gene expression. Most of these targeted genes could express the transcription factors which controlled the expression of nearly all genes. Besides, another crucial part of the predicted targets were diverse sorts of enzymes such as protein kinase, which may participate in various signaling 
Table IV. The top five pathways regulated by all $11 \mathrm{CA}-\mathrm{miRNAs.}$

\begin{tabular}{llcrr}
\hline Pathway DB & \multicolumn{1}{c}{ Name } & Hits & Total & Percent \\
\hline KEGG & Pathways in cancer & 141 & 343 & $41.11 \%$ \\
& MAPK signaling pathway & 125 & 284 & 240 \\
& Endocytosis & 103 & 198 & $42.92 \%$ \\
& HTLV-I infection & 93 & 228 & $46.97 \%$ \\
& Regulation of actin cytoskeleton & 93 & $40.79 \%$ \\
\hline
\end{tabular}

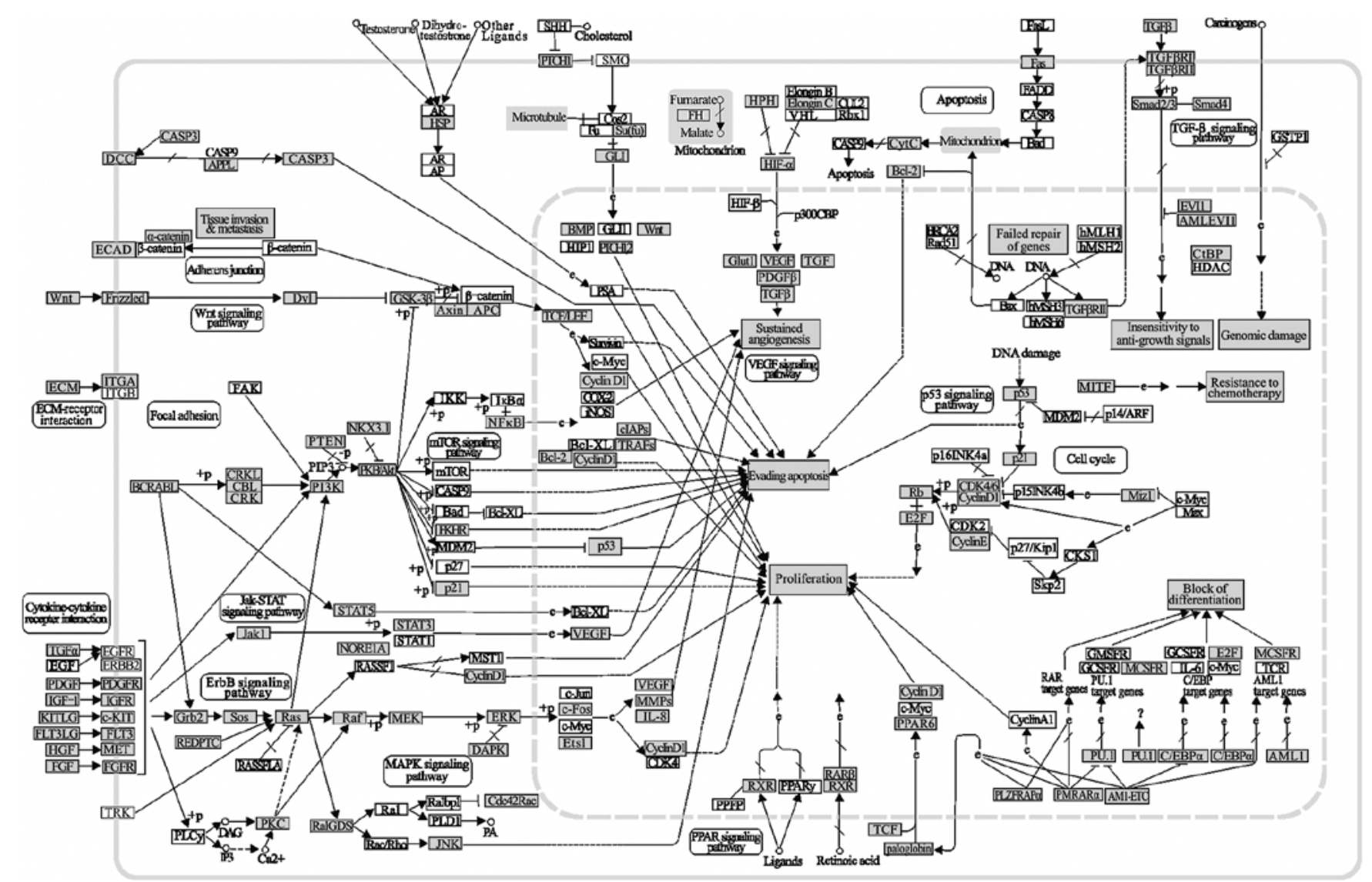

Figure 2. CA-miRNA regulation of pathways in cancer biological map. Grey boxes show objects that can be regulated by CA-miRNAs with numbering corresponding to that seen in Table IV. Solid arrows, activation; dotted arrows, indirect effect; $\perp$, inhibition. Letters on lines denote the type of regulation as follows: $+\mathrm{p}$, phosphorylation; - $\mathrm{p}$, dephosphorylation; +u, ubiquitination; +g, glycosylation; +m, methylation.

pathways. A protein kinase which modifies other proteins by chemically adding phosphate groups to them (phosphorylation) is one of the largest and most influential of gene families: constituting some $2 \%$ of the proteome, they regulate almost all biochemical pathways and may phosphorylate up to $30 \%$ of the proteome. Interestingly, beside the CA-miRNAs, other miRNAs also seem to have the same most common targeted genes, which may be a general character of miRNA regulation (55).

Over-represented protein classes of target genes are transcription factors, protein kinases, receptors, components of the miRNA machinery, and other proteins involved in translational regulation, as well as components of the ubiquitin machinery, which is crucial in the maintenance of normal cell life and this result also represented novel feedback loops in gene regulation similarly to previous research (56). As miRNAs seem to play a role as more refined regulators of gene expression, the minor percent of the targets contain diverse proteins such as cytokine, protease, immunoglobulin superfamily cell adhesion molecule, ATP-binding cassette $(\mathrm{ABC})$ transporter, and actin family cytoskeletal protein.

The largest number of genes are targeted by the miR-17-92 cluster, which is not only because this miRNA cluster contain more family members but also commit more dominant functions except transcription factors and protein kinases such as signaling molecule, G-protein coupled receptor, and hydrolase. On the other hand, as a less significant regulator, miR-206 targets the minimum amount of genes, which may function as G-protein modulator, dehydrogenase, and hydrolase. In agree- 


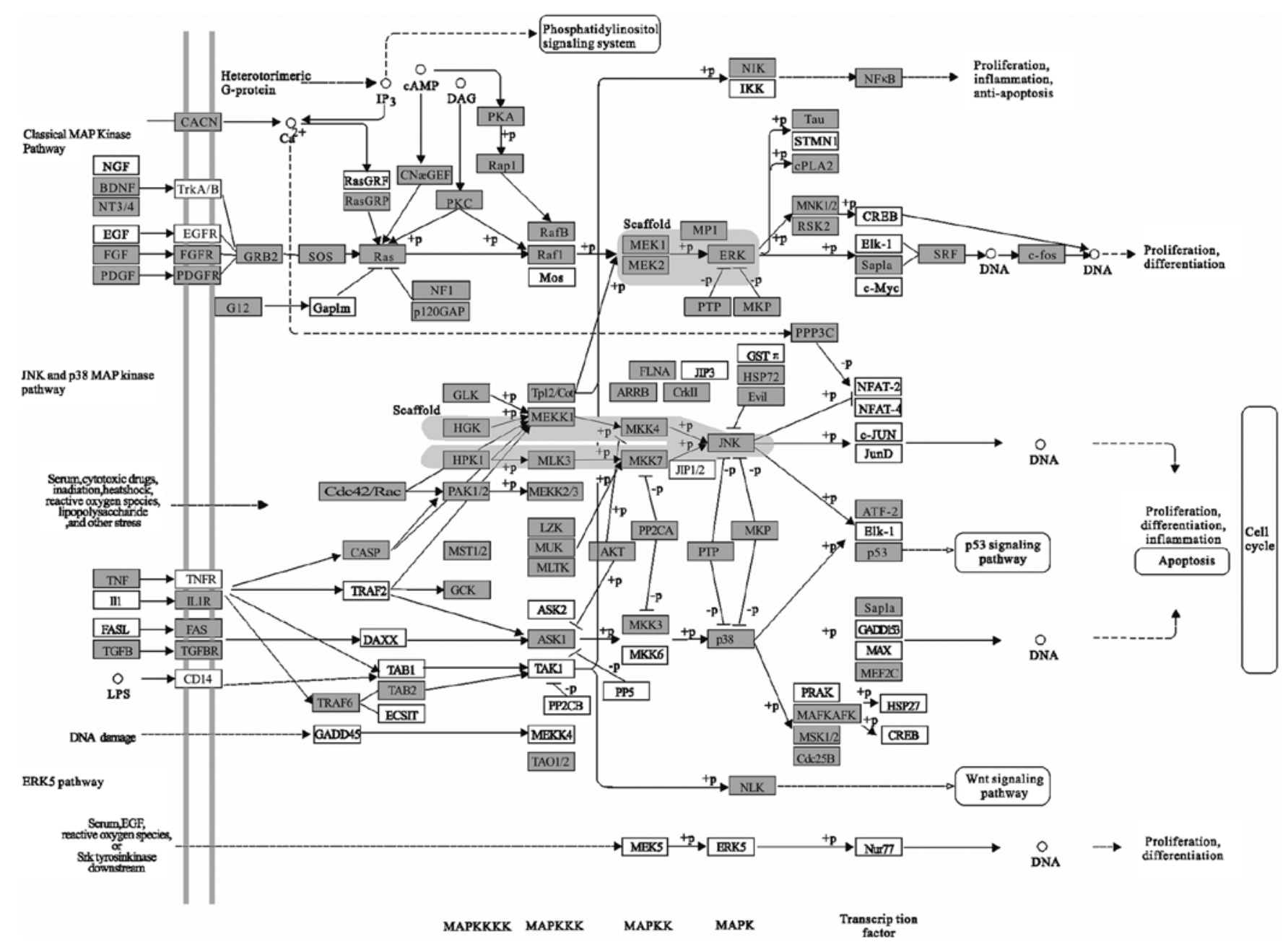

Figure 3. Biological map of CA-miRNA regulation of MAPK signaling pathway. Grey boxes show objects that can be regulated by CA-miRNAs with numbering corresponding to that seen in Table IV. Solid arrows, activation; dotted arrows, indirect effect; $\perp$, inhibition. Letters on lines denote the type of regulation as follows: + p, phosphorylation; -p, dephosphorylation; +u, ubiquitination; +g, glycosylation; +m, methylation.

ment with our results, some research groups have found that miRNA oncogenes and tumor suppressors clearly show different patterns in function, evolutionary rate, expression, chromosome distribution, molecule size, free energy, transcription factors and targets (57).

Molecular function, biological process and signal pathway analysis of targets related to each CA-miRNA. We scored the list of genes for each miRNA against molecular function, biological process and canonical pathways. For each miRNA, the top five rank for each analysis is shown in Tables II and III. The targets for the CA-miRNAs were most prominently predicted to function in regulation of transcription, which is the dominant process of controlling gene expression. Carcinogenesis in humans is a multistep process and that these steps reflect genetic alterations that drive the progressive transformation of normal human cells into highly malignant derivatives. Similarly, pathways in cancer and MAPK signaling pathway were the most-observed overlaps between the pathways for these CA-miRNAs, suggesting that these miRNAs may probably regulate carcinogenesis mainly through the two pathways. The results indicated that those miRs are closely associated with cancers, consistent with current observations described in cancer associated miRNAs section.
Pathway mapping of cancer-associated miRNA targets. The top five pathways regulated by the CA-miRNAs are shown in Table IV. It inferred that these 11 CA-miRNAs participate in carcinogenesis mainly through the five pathways concerned with morphological changes, intercellular communication and invasion of cancer cells. Three out of these top 5 pathways (pathways in cancer, endocytosis and regulation of actin cytoskeleton) are reported in the biological pathway analysis for prostate cancer (58). Admittedly, there are definitely other cancer-related pathways not emerged in the Rank Five list. It may be because these targeted genes mainly occupied a large percentage in the five pathways and they are still closely connected with other cancer-related pathways.

Pathways in cancer are highly saturated with gene targets of the CA-miRNAs (Fig. 2). This kind of pathway clearly demonstrated the acquisition of biological capabilities such as block of differentiation, resistance to apoptosis, unlimited replicative potential, sustained angiogenesis, tissue invasion and metastasis for the transformation from normal cells into highly malignant tumor cells. The effects of alterations on many oncogenes and tumor suppressor genes are complex due to the high number of changes in the interactions of the biological pathways involved. However, more common abnormalities in oncogenes and tumor 


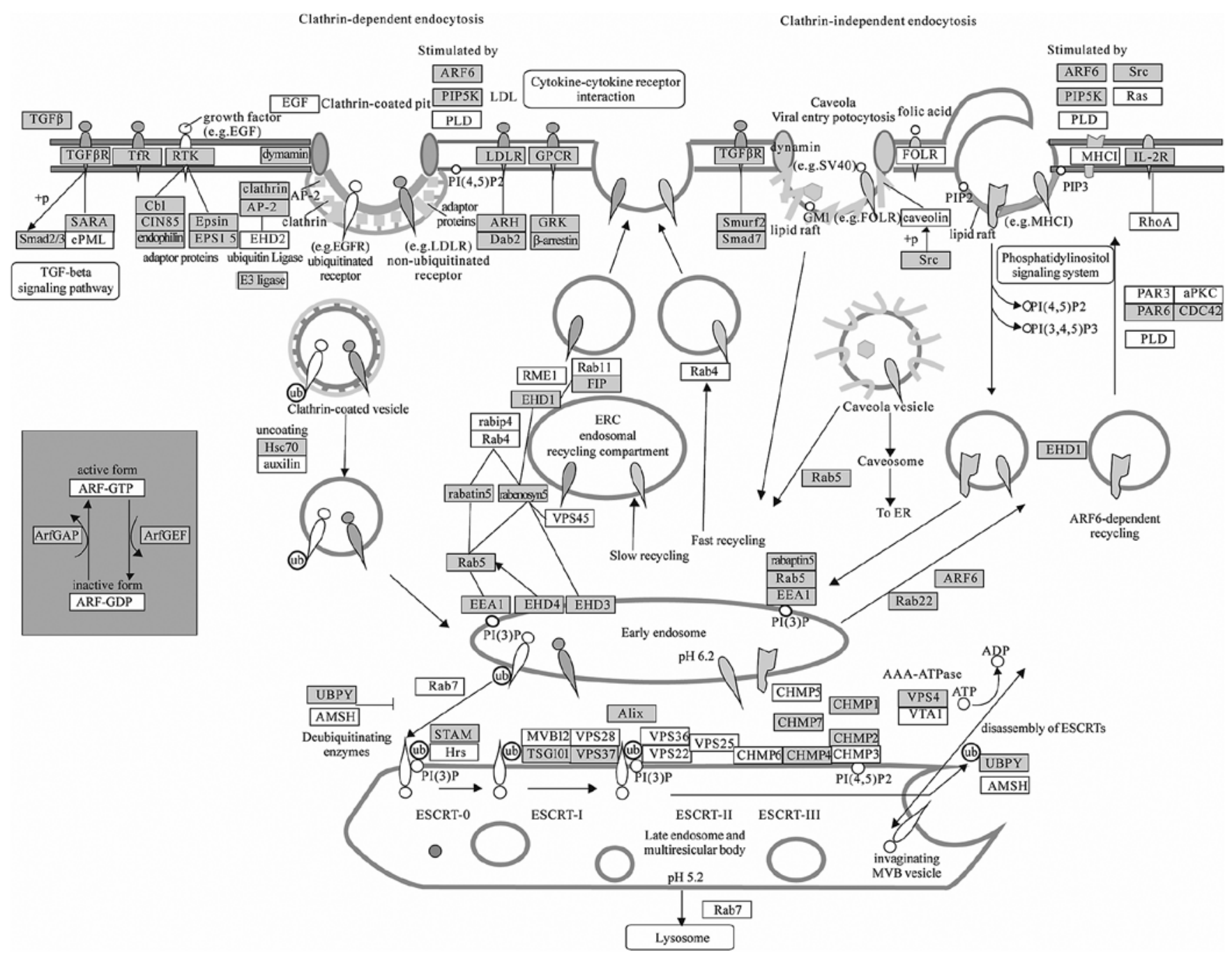

Figure 4. Biological map of CA-miRNA regulation of endocytosis. Grey boxes show objects that can be regulated by CA-miRNAs with numbering corresponding to that seen in Table IV. Solid arrows, activation; dotted arrows, indirect effect; $\perp$, inhibition. Letters on lines denote the type of regulation as follows: $+\mathrm{p}$, phosphorylation; -p, dephosphorylation; +u, ubiquitination; +g, glycosylation; +m, methylation.

suppressor genes regulated by CA-miRNAs can be potential therapeutic targets. Indeed, miRNA targeted genes in grey such as Wnt, STAT3, p21, P53, BCL-2, Fas, TGF- $\beta$, and Rb are directly related with cancer (Fig. 2).

Mitogen-activated protein kinase (MAPK) pathway functions as integrating signals that affect proliferation, differentiation, survival and migration (Fig. 3). MAPK signaling is tightly regulated so that optimal biological activities are achieved and health is maintained. This pathway activation is a frequent event in human cancer and is often the result of activating mutations in the BRAF and RAS oncogenes. There are three main sub-families of MAPK pathways in humans (classical MAPK pathways, JNK and p38 MAPK pathway and ERK5 pathway), whose functions are regulated by activators, inactivators, substrates and scaffolds, which together form delicate signaling cascades in response to different extracellular or intracellular stimulation. Unscheduled proliferation is a hallmark of cancer, and the JNK and p38 MAPK pathways regulate cell cycle progression at different transition points by both transcription-dependent and transcription-independent mechanisms. Members of MAP kinase (MAPK) family are evolutionarily conserved regulators that mediate signal transduction and play essential roles in various physiological processes. Consistent with the importance of these events in tumorigenesis, MAPK signaling is closely associated with cancers in humans. The MAPKs are activated by mitogens and were found to be upregulated in human tumors; this finding has led to the development of inhibitors of this pathway for cancer therapeutics. Studies in mouse models have been essential to better understand how these MAPKs control cancer development, and these models are expected to provide new strategies for the design of improved therapeutic approaches (59). Small-molecule inhibitors designed to target various steps of this pathway have entered clinical trials (60). Pharmacological inhibition of the kinase JNK blocked induction of oncomiR miR-155 in response to either polyriboinosinic:polyribocytidylic acid or TNF- $\alpha$, suggesting that miR-155-inducing signals use the JNK pathway (61). In addition, miR-141 and miR-200a target p38a and modulate the oxidative stress response (62). These previous results indicate that miRNAs may be a promising clinical treatment for cancer through the MAPK pathway. 


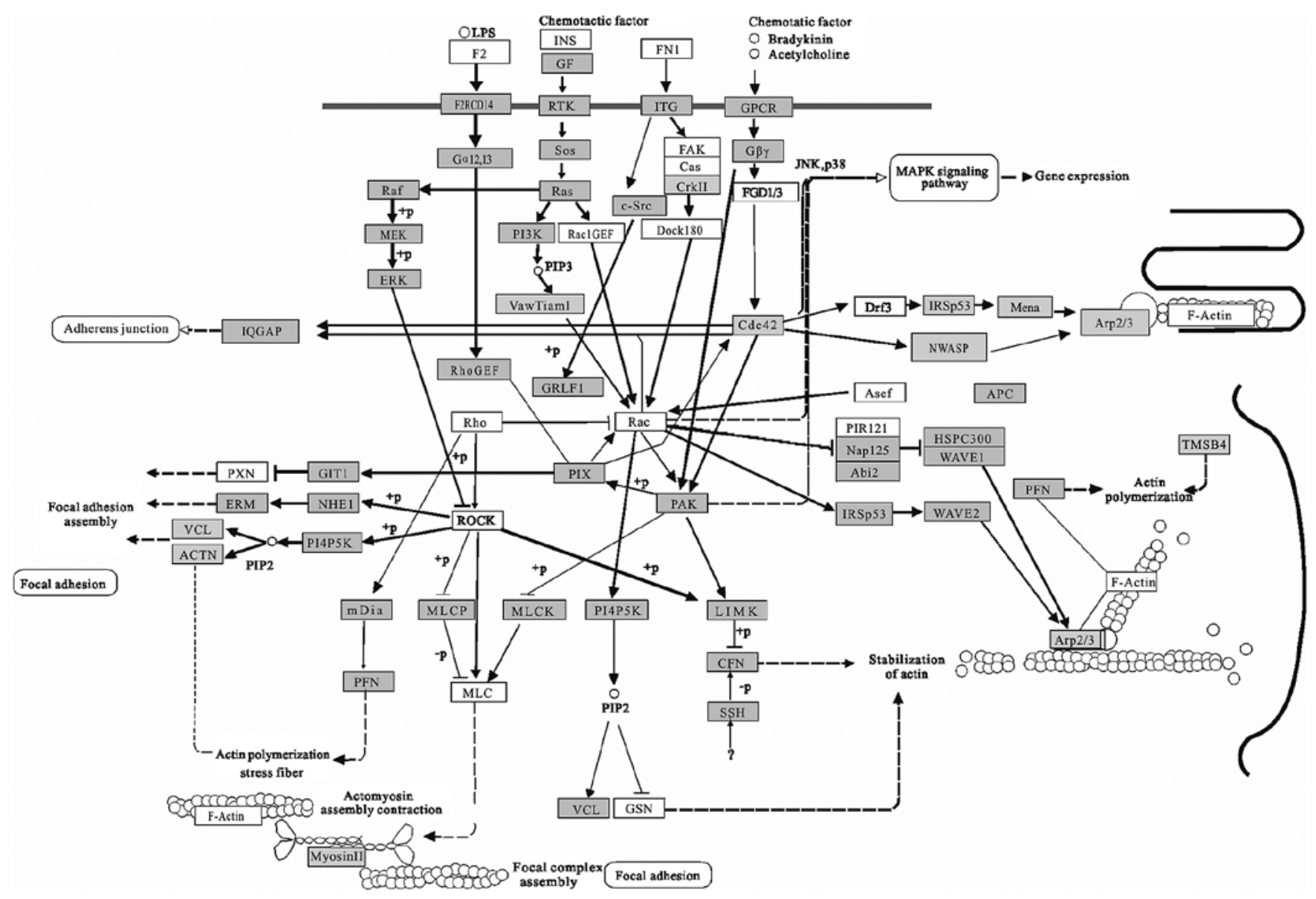

Figure 5. Biological map of CA-miRNA regulation of HTLV-1 infection. Grey boxes show objects that can be regulated by CA-miRNAs with numbering corresponding to that seen in Table IV. Solid arrows, activation; dotted arrows, indirect effect; $\perp$, inhibition. Letters on lines denote the type of regulation as follows: $+\mathrm{p}$, phosphorylation; - $\mathrm{p}$, dephosphorylation; $+\mathrm{u}$, ubiquitination; $+\mathrm{g}$, glycosylation; $+\mathrm{m}$, methylation.

Endocytosis (Fig. 4) has been regarded as a long-term mechanism of signal attenuation via receptor clearance from the cell surface. Additional and quite unexpected functions for endocytosis have emerged, which, together with its attenuation function, project a central role for this process in cellular homeostasis and control of proliferation (63). Subversion of endocytic control is thus predicted to play a causative role in hyper-proliferative conditions, first and foremost cancer (63). Recently, research has revealed that microenvironment around tumor cells contains various circulating miRNAs secreted by microvesicles or exosomes, which may enter into other surrounded cells by endocytosis $(64,65)$. Therefore, this pathway cluster analysis suggests that endocytosis needs to be paid more attention as a novel mechanism of intercellular communication of tumor cells.

The human T cell leukemia virus type I (HTLV-I) infection (Fig. 5) is associated with adult T cell leukemia/lymphoma (ATL). ATL is a highly aggressive neoplastic disease of CD4 positive T lymphocyte, which is featured by the pleomorphic tumor cells with hyper-segmented nuclei, called 'flower cell' (66). HTLV-I, as an oncogenic retrovirus, encodes an oncogenic protein, Tax, which interferes with several signaling pathways related to anti-apoptosis or cell proliferation. The ability of Tax to both transcriptionally regulate cellular gene expression and to functionally inactivate proteins involved in cell cycle progression and DNA repair provide the basis for Tax-mediated transformation and leukemogenesis (67). The modulation of the signaling by Tax involves its binding to transcription factors like CREB/ ATF, NF- $\kappa B$, SRF and NFAT.

Regulation of actin cytoskeleton (Fig. 6) may be involved in morphological changes of cancer cells. Several studies have demonstrated that molecules that link migratory signals to the actin cytoskeleton are upregulated in invasive and metastatic cancer cells (68). Aberrant regulation of cell migration drives progression of cancer invasion and metastasis (69-71). This pathway seems to be an overlap with those participated in senescent cells, which also undergo changes in morphology, becoming large and flattened (72). Beside this pathway, many cancer-related pathways overlap with that involved in senescence such as inflammatory pathway, IGF pathway, p16-p21 pathway and $\mathrm{p} 53$ pathway. In terms of the pathway, cancer and senescence seem to share many same biological processes and cancer is defined as a typical aging related disease (73). For the ability of targeting many different genes, miRNAs provide a mechanism through which widespread alternations could be induced.

In this study, we have used pathway mapping and theoretical gene target identification to create a biological framework by which to test the relevance of miRNAs in cancer induction. The identification of CA-miRNAs related pathways with the 


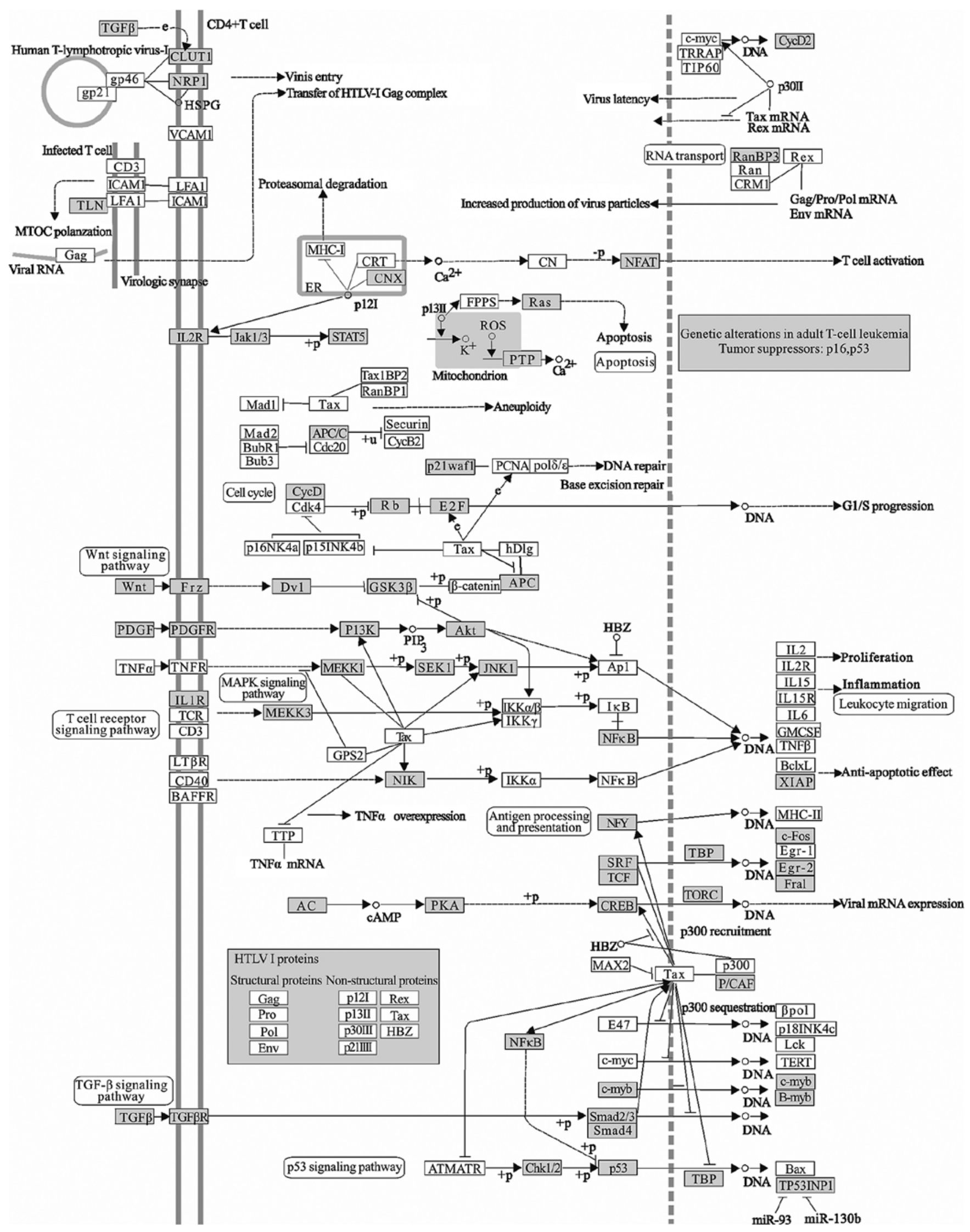

Figure 6. Biological map of CA-miRNA regulation of actin cytoskeleton. Grey boxes show objects that can be regulated by CA-miRNAs with numbering corresponding to that seen in Table IV. Solid arrows, activation; dotted arrows, indirect effect; $\perp$, inhibition. Letters on lines denote the type of regulation as follows: $+\mathrm{p}$, phosphorylation; -p, dephosphorylation; +u, ubiquitination; +g, glycosylation; +m, methylation. 
ability to regulate a complex pathological process such as cancer, can be better using bioinformatic techniques followed by experimental validation.

\section{Acknowledgements}

This project is supported by grants from National Natural Science Foundation of China (31000323, 31070672), Specialized Research Fund for the Doctoral Program of Higher Education of China (20100091120023) and Fundamental Research Funds for the Central Universities (1095020823).

\section{References}

1. Valencia-Sanchez MA, Liu J, Hannon GJ and Parker R: Control of translation and mRNA degradation by miRNAs and siRNAs. Genes Dev 20: 515-524, 2006

2. Lewis BP, Burge CB and Bartel DP: Conserved seed pairing, often flanked by adenosines, indicates that thousands of human genes are microRNA targets. Cell 120: 15-20, 2005.

3. Zhang L, Hou D, Chen X, et al: Exogenous plant MIR168a specifically targets mammalian LDLRAP1: evidence of crosskingdom regulation by microRNA. Cell Res 22: 107-126, 2012.

4. Ma J and Huang Y: Post-transcriptional regulation of miRNA biogenesis and functions. Front Biol 5: 32-40, 2010.

5. Calin GA and Croce CM: MicroRNA signatures in human cancers. Nat Rev Cancer 6: 857-866, 2006.

6. Esquela-Kerscher A and Slack FJ: Oncomirs - microRNAs with a role in cancer. Nat Rev Cancer 6: 259-269, 2006.

7. Garzon R, Calin GA and Croce CM: MicroRNAs in cancer. Annu Rev Med 60: 167-179, 2009.

8. Kwak PB, Iwasaki S and Tomari Y: The microRNA pathway and cancer. Cancer Sci 101: 2309-2315, 2010.

9. Ming M, Zhao X, Zhao Z, Liu B and Bao J: MicroRNA regulation of programmed cell death pathways in cancer. Curr Chem Biol 6: 53-59, 2012.

10. Loscalzo J, Kohane I and Barabasi AL: Human disease classification in the postgenomic era: a complex systems approach to human pathobiology. Mol Syst Biol 3: 124, 2007.

11. Calin GA, Sevignani C, Dumitru CD, et al: Human microRNA genes are frequently located at fragile sites and genomic regions involved in cancers. Proc Natl Acad Sci USA 101: 2999-3004, 2004.

12. Calin GA, Dumitru CD, Shimizu M, et al: Frequent deletions and down-regulation of micro- RNA genes miR15 and miR16 at $13 q 14$ in chronic lymphocytic leukemia. Proc Natl Acad Sci USA 99: 15524-15529, 2002.

13. He L, Thomson JM, Hemann MT, et al: A microRNA polycistron as a potential human oncogene. Nature 435: 828-833, 2005.

14. Tagawa $\mathrm{H}$ and Seto $\mathrm{M}$ : A microRNA cluster as a target of genomic amplification in malignant lymphoma. Leukemia 19 2013-2016, 2005.

15. Farazi TA, Spitzer JI, Morozov P and Tuschl T: miRNAs in human cancer. J Pathol 223: 102-115, 2011.

16. Pei Y, Wang Z, Fei F, Shao Z, Huang W and Zhang X: Bioinformatics study indicates possible microRNA-regulated pathways in the differentiation of breast cancer. Chin Sci Bull 55: 927-936, 2010.

17. Huang da W, Sherman BT, Tan Q, et al: The DAVID gene functional classification tool: a novel biological module-centric algorithm to functionally analyze large gene lists. Genome Biol 8: R183, 2007.

18. Kanehisa M, Araki M, Goto S, et al: KEGG for linking genomes to life and the environment. Nucleic Acids Res 36: D480-D484, 2008.

19. Johnson SM, Grosshans H, Shingara J, et al: RAS is regulated by the let-7 microRNA family. Cell 120: 635-647, 2005

20. Johnson CD, Esquela-Kerscher A, Stefani G, et al: The let-7 microRNA represses cell proliferation pathways in human cells. Cancer Res 67: 7713-7722, 2007.

21. Adams BD, Guttilla IK and White BA: Involvement of microRNAs in breast cancer. Semin Reprod Med 26: 522-536, 2008.

22. Laios A, O'Toole S, Flavin R, et al: Potential role of miR-9 and miR-223 in recurrent ovarian cancer. Mol Cancer 7: 35, 2008.
23. Lehmann U, Hasemeier B, Christgen M, et al: Epigenetic inactivation of microRNA gene hsa-mir-9-1 in human breast cancer. J Pathol 214: 17-24, 2008.

24. Ferretti E, De Smaele E, Po A, et al: MicroRNA profiling in human medulloblastoma. Int J Cancer 124: 568-577, 2009.

25. Sun $\mathrm{Y}, \mathrm{Wu} \mathrm{J}, \mathrm{Wu} \mathrm{SH}$, et al: Expression profile of microRNAs in c-Myc induced mouse mammary tumors. Breast Cancer Res Treat 118: 185-196, 2009.

26. Ma L, Young J, Prabhala $\mathrm{H}$, et al: $\mathrm{miR}-9$, a MYC/MYCNactivated microRNA, regulates E-cadherin and cancer metastasis. Nat Cell Biol 12: 247-256, 2010.

27. Bonci D, Coppola V, Musumeci M, et al: The miR-15a-miR-16-1 cluster controls prostate cancer by targeting multiple oncogenic activities. Nat Med 14: 1271-1277, 2008.

28. Calin GA, Cimmino A, Fabbri M, et al: MiR-15a and miR-16-1 cluster functions in human leukemia. Proc Natl Acad Sci USA 105: 5166-5171, 2008

29. Mendell JT: miRiad roles for the miR-17-92 cluster in development and disease. Cell 133: 217-222, 2008.

30. Uziel T, Karginov FV, Xie S, et al: The miR-17 92 cluster collaborates with the Sonic Hedgehog pathway in medulloblastoma. Proc Natl Acad Sci USA 106: 2812-2817, 2009.

31. O'Day E and Lal A: MicroRNAs and their target gene networks in breast cancer. Breast Cancer Res 12: 201, 2010.

32. Lawrie CH, Soneji S, Marafioti T, et al: MicroRNA expression distinguishes between germinal center B cell-like and activated B cell-like subtypes of diffuse large B cell lymphoma. Int J Cancer 121: 1156-1161, 2007.

33. Sander S, Bullinger L, Klapproth K, et al: MYC stimulates EZH2 expression by repression of its negative regulator miR-26a. Blood 112: 4202-4212, 2008.

34. Kota J, Chivukula RR, O'Donnell KA, et al: Therapeutic microRNA delivery suppresses tumorigenesis in a murine liver cancer model. Cell 137: 1005-1017, 2009.

35. Visone R, Pallante P, Vecchione A, et al: Specific microRNAs are downregulated in human thyroid anaplastic carcinomas. Oncogene 26: 7590-7595, 2007.

36. Kim H, Huang W, Jiang X, Pennicooke B, Park PJ and Johnson MD: Integrative genome analysis reveals an oncomir/ oncogene cluster regulating glioblastoma survivorship. Proc Natl Acad Sci USA 107: 2183-2188, 2010.

37. Gallardo E, Navarro A, Vinolas N, et al: miR-34a as a prognostic marker of relapse in surgically resected non-small-cell lung cancer. Carcinogenesis 30: 1903-1909, 2009.

38. Cole KA, Attiyeh EF, Mosse YP, et al: A functional screen identifies miR-34a as a candidate neuroblastoma tumor suppressor gene. Mol Cancer Res 6: 735-742, 2008

39. Li N, Fu H, Tie Y, et al: miR-34a inhibits migration and invasion by down-regulation of c-Met expression in human hepatocellular carcinoma cells. Cancer Lett 275: 44-53, 2009.

40. Volinia S, Calin GA, Liu CG, et al: A microRNA expression signature of human solid tumors defines cancer gene targets. Proc Natl Acad Sci USA 103: 2257-2261, 2006.

41. Yanaihara N, Caplen N, Bowman E, et al: Unique microRNA molecular profiles in lung cancer diagnosis and prognosis. Cancer Cell 9: 189-198, 2006.

42. Nakada C, Matsuura K, Tsukamoto Y, et al: Genome-wide microRNA expression profiling in renal cell carcinoma: significant down-regulation of miR-141 and miR-200c. J Pathol 216: 418-427, 2008

43. Du Y, Xu Y, Ding L, et al: Down-regulation of miR-141 in gastric cancer and its involvement in cell growth. J Gastroenterol 44: 556-561, 2009.

44. Nie W, Tang L, Zhang H, et al: Structural analysis of the EGFR TK domain and potential implications for EGFR targeted therapy. Int J Oncol 40: 1763-1769, 2012.

45. Adam L, Zhong M, Choi W, et al: miR-200 expression regulates epithelial-to-mesenchymal transition in bladder cancer cells and reverses resistance to epidermal growth factor receptor therapy. Clin Cancer Res 15: 5060-5072, 2009.

46. Bendoraite A, Knouf EC, Garg KS, et al: Regulation of miR-200 family microRNAs and ZEB transcription factors in ovarian cancer: Evidence supporting a mesothelial-to-epithelial transition. Gynecol Oncol 116: 117-125, 2010.

47. Gandellini P, Folini M, Longoni N, et al: miR-205 exerts tumor-suppressive functions in human prostate through down-regulation of protein kinase Cepsilon. Cancer Res 69: 2287-2295, 2009.

48. Wiklund ED, Bramsen JB, Hulf T, et al: Coordinated epigenetic repression of the miR-200 family and miR-205 in invasive bladder cancer. Int J Cancer 128: 1327-1334, 2011. 
49. Iorio MV, Casalini P, Piovan C, et al: microRNA-205 regulates HER3 in human breast cancer. Cancer Res 69: 2195-2200, 2009.

50. Iorio MV, Visone R, Di Leva G, et al: MicroRNA signatures in human ovarian cancer. Cancer Res 67: 8699-8707, 2007.

51. Taulli R, Bersani F, Foglizzo V, et al: The muscle-specific microRNA miR-206 blocks human rhabdomyosarcoma growth in xenotransplanted mice by promoting myogenic differentiation. J Clin Invest 119: 2366-2378, 2009.

52. Negrini M and Calin GA: Breast cancer metastasis: a microRNA story. Breast Cancer Res 10: 203, 2008

53. Hobert O: miRNAs play a tune. Cell 131: 22-24, 2007.

54. Hammond SM: MicroRNAs as oncogenes. Curr Opin Genet Dev 16: 4-9, 2006.

55. Yang H, Zhang HY, Zhu L, Zhang CY, Li DH: Identification and characterization of microRNAs in Macaca fascicularis by EST analysis. Comp Funct Genom: Jul 5, 2012 (Epub ahead of print).

56. John B, Enright AJ, Aravin A, Tuschl T, Sander C and Marks DS: Human MicroRNA targets. PLoS Biol 2: e363, 2004.

57. Wang D, Qiu C, Zhang H, Wang J, Cui Q and Yin Y: Human microRNA oncogenes and tumor suppressors show significantly different biological patterns: from functions to targets. PLoS One 5: e13067, 2010.

58. Yifei T, Jiajia C, Cheng L, Kaipia A and Bairong S: MicroRNA expression analysis reveals significant biological pathways in human prostate cancer. Systems Biology (ISB), 2011 IEEE International Conference on 203-210.

59. Wagner EF and Nebreda AR: Signal integration by JNK and p38 MAPK pathways in cancer development. Nat Rev Cancer 9: 537-549, 2009.

60. Sebolt-Leopold JS and Herrera R: Targeting the mitogenactivated protein kinase cascade to treat cancer. Nat Rev Cancer 4: 937-947, 2004.
61. O'Connell RM, Taganov KD, Boldin MP, Cheng G and Baltimore D: MicroRNA-155 is induced during the macrophage inflammatory response. Proc Natl Acad Sci USA 104: 1604-1609, 2007.

62. Mateescu B, Batista L, Cardon M, et al: miR-141 and miR-200a act on ovarian tumorigenesis by controlling oxidative stress response. Nat Med 17: 1627-1635, 2011.

63. Polo S, Pece S and Di Fiore PP: Endocytosis and cancer. Curr Opin Cell Biol 16: 156-161, 2004

64. Al-Nedawi K, Meehan B, Micallef J, et al: Intercellular transfer of the oncogenic receptor EGFRvIII by microvesicles derived from tumour cells. Nat Cell Biol 10: 619-624, 2008.

65. Simons M and Raposo G: Exosomes - vesicular carriers for intercellular communication. Curr Opin Cell Biol 21: 575-581, 2009.

66. Yasunaga J and Matsuoka M: HTLV-I and leukemogenesis. Uirusu 56: 241-249, 2006 (In Japanese).

67. Gatza ML, Watt JC and Marriott SJ: Cellular transformation by the HTLV-I Tax protein, a jack-of-all-trades. Oncogene 22: 5141-5149, 2003

68. Yamaguchi $\mathrm{H}$ and Condeelis J: Regulation of the actin cytoskeleton in cancer cell migration and invasion. Biochim Biophys Acta 1773: 642-652, 2007

69. Condeelis J, Singer RH and Segall JE: The Great Escape: when cancer cells hijack the genes for chemotaxis and motility. Annu Rev Cell Dev Biol 21: 695, 2005.

70. Sahai E: Mechanisms of cancer cell invasion. Curr Opin Genet Dev 15: 87-96, 2005.

71. Yamaguchi $\mathrm{H}$, Wyckoff $\mathrm{J}$ and Condeelis $\mathrm{J}$ : Cell migration in tumors. Curr Opin Cell Biol 17: 559-564, 2005.

72. Tominaga K, Olgun A, Smith JR and Pereira-Smith OM: Genetics of cellular senescence. Mech Ageing Dev 123: 927-936, 2002.

73. Burkle A, Caselli G, Franceschi C, et al: Pathophysiology of ageing, longevity and age related diseases. Immun Ageing 4: 4, 2007. 